\title{
Mutant NDUFS3 subunit of mitochondrial complex I causes Leigh syndrome
}

\author{
P Bénit, A Slama, F Cartault, I Giurgea, D Chretien, S Lebon, C Marsac, A Munnich, A Rötig, \\ P Rustin
}

\begin{abstract}
Respiratory chain complex I deficiency represents a genetically heterogeneous group of diseases resulting from mutations in mitochondrial or nuclear genes. Mutations have been reported in 13 of the 14 subunits encoding the core of complex I (seven mitochondrial and six nuclear genes) and these result in Leigh or Leigh-like syndromes or cardiomyopathy. In this study, a combination of denaturing high performance liquid chromatography and sequence analysis was used to study the NDUFS3 gene in a series of complex I deficient patients. Mutations found in this gene (NADH dehydrogenase iron-sulphur protein 3), coding for the seventh and last subunit of complex I core, were shown to cause late onset Leigh syndrome, optic atrophy, and complex I deficiency. A biochemical diagnosis of complex I deficiency on cultured amniocytes from a later pregnancy was confirmed through the identification of disease causing NDUFS3 mutations in these cells. While mutations in the NDUFS3 gene thus result in Leigh syndrome, a dissimilar clinical phenotype is observed in mutations in the NDUFV2 and NDUFS2 genes, resulting in encephalomyopathy and cardiomyopathy. The reasons for these differences are uncertain.
\end{abstract}

R educed nicotinamide adenine dinucleotide (NADH):ubiquinone oxidoreductase (mitochondrial respiratory chain complex I) catalyses electron transfer from NADH to the ubiquinone pool, with simultaneous vectorial proton pumping across the inner mitochondrial (mt) membrane. Electrons are transferred from NADH to the primary electron acceptor, a non-covalently bound flavin mononucleotide (FMN), and thence, through a series of ironsulphur clusters, to bound ubiquinone. This multisubunit complex comprises more than 40 subunits that are encoded by either the mtDNA or the nuclear genome. ${ }^{1}$ Using chaotrophic agents, the complex has been separated into three fractions. ${ }^{2}$ The largest (hydrophobic) membrane fraction (HP) contains all the seven mtDNA encoded subunits and 25 nuclearly encoded subunits, while the matrix protruding fractions which harbour the flavin and the ironsulphur cluster moieties (FP and IP fractions, of three and seven subunits, respectively) are exclusively encoded by nuclear genes. ${ }^{3}$

Mutations have been identified in all the seven subunits encoded by the mtDNA, resulting in a variety of clinical symptoms ranging from organ specific (for example, Leber hereditary optic neuropathy, LHON) to multivisceral diseases (such as mitochondrial encephalomyopathy with lactic acidosis and stroke-like episodes, MELAS). ${ }^{4}$ In addition, mutations have been found in seven nuclear genes encoding proteins of the HP, FP, and IP fractions. Mutations of five of these nuclear genes (NDUFS1, NDUFS4, NDUFS7, NDUFS8, and $N D U F V I)^{5-11}$ result in neurological diseases, mostly Leigh or Leigh-like syndromes, while mutations of the NDUFS2 and NDUFV2 genes are associated with hypertrophic cardiomyopathy and encephalomyopathy. ${ }^{12}{ }^{13}$ Except for NDUFS4, the seven nuclearly encoded subunits (NDUFS1, NDUFS2, NDUFS3, NDUFS7, NDUFS8, NDUFV1, and NDUFV2) and the seven mitochondrially encoded subunits (ND1, ND2, ND3, ND4, ND4L, ND5, ND6) are conserved across species, especially as they are constitutive of the core of complex I, considered to be essential for the catalysis of electron transfer from NADH to ubiquinone, and for the generation of the proton motive force. In this study, we show that mutations in the NDUFS3 gene (MIM 603846), encoding the seventh and last constitutive subunit of the complex I core, also result in Leigh syndrome.

\section{METHODS}

Patient 1, a boy, was the first child of healthy unrelated parents in Réunion Island. He was born after an uncomplicated full term pregnancy (birth weight $2880 \mathrm{~g}$, height $50 \mathrm{~cm}$, head circumference $33 \mathrm{~cm}$ ). At nine months of age, he had a single episode of febrile convulsions. His psychomotor development was normal until nine years of age, but a kyphoscoliosis had been noted.

At nine years he developed a persistent stiff neck. Brain and medullary magnetic resonance imaging (MRI), electroencephalography (EEG), and electromyography (EMG) were normal. He gradually developed severe axial dystonia with oral and pharyngeal motor dysfunction, dysphagia, and a tetraparetic syndrome. Ocular movements were normal, but the retinal fundus showed a mild pallor of the optic discs. Measurements of visual evoked potentials showed a diminution in retroretinal conduction suggestive of optic nerve atrophy.

At 10 years, cerebral MRI detected a high T2 signal intensity in the putamen, the white matter, and the brain stem. At that time, CSF lactate was $2.7 \mathrm{mM}$ (control below 2 $\mathrm{mM})$. A complex I deficiency was identified in a skeletal muscle biopsy

Two years later, he developed an acute pancreatitis and a severe respiratory insufficiency that required tracheal intubation and respiratory support for six weeks, and then a tracheostomy.

He died one and half years later after rapid multisystem deterioration. Biochemical prenatal diagnosis was offered and revealed complex I deficiency in a third pregnancy (patient 2). A younger brother is healthy.

Polarographic tests and spectrophotometric assays were carried out on skeletal muscle mitochondria and cultured skin fibroblasts as previously described. ${ }^{14}{ }^{15}$ Total RNAs were extracted from cultured skin fibroblasts using the Rnasin kit (Qiagen, Courtabeuf, France) and reverse transcribed using random hexamer primers (GenAmp RNA PCR core kit, PE 
Applied Biosystems, Perkin Elmer, France). Reverse transcriptase polymerase chain reaction (RT-PCR) amplification of the NDUFS3 specific RNA was done in two overlapping fragments spanning the entire coding region of the gene. Fragment 1 was amplified using oligonucleotides 5'-GGAA GGTGAACAGTGTGGCC-3' (forward) and 5'-GCAGGGT GTAGTAGTGCAGAC-3' (reverse). Fragment 2 was amplified using oligonucleotides 5'-ATACAATGTATAATCGAAAGCCAG3' (forward) and 5'-CATATTTTATTTCTCTAGTGACAT-3' (reverse). Amplification products were mixed with control PCR products, denatured for 10 minutes at $96^{\circ} \mathrm{C}$ and then gradually reannealed by decreasing sample temperature from $96^{\circ} \mathrm{C}$ to $30^{\circ} \mathrm{C}$. The annealed specimens $(7 \mu \mathrm{l})$ were loaded onto a DNA Sep column (Transgenomic, city, France) by means of a Dynamax automatic sample injector model AI-1A (Transgenomic). Sequencing of the abnormal D-HPLC profiles was undertaken directly using a Big Dye terminator cycle sequencing kit (ABI Prism, PE Applied Biosystems).

\section{RESULTS}

Polarographic assays showed low pyruvate plus malate oxidation in skeletal muscle mitochondria isolated from patient 1 compared with control (table 1). Activity ratios ${ }^{16}$ showed that complex I dependent activities were significantly decreased (that is, pyruvate plus malate oxidation, NADH cytochrome $c$ reductase activity): complex IV/I activity ratios showed a $50 \%$ deficiency in complex I activity in skeletal muscle and cultured skin fibroblasts of patient 1. A similar figure was obtained in the cultured amniocytes of patient 2 (the fetus), with a $50 \%$ decrease in $\mathrm{NADH}$ quinone reductase activity (table 1). This partial defect is possibly consistent with a complete inhibition of complex I dependent substrate oxidation in vivo. ${ }^{17}$

RT-PCR amplification and D-HPLC analysis of NDUFS3 mRNAs from cultured skin fibroblasts of patient 1 detected two abnormal patterns of migration (fig 1). Direct sequencing of the abnormal amplification product revealed compound heterozygosity for two distinct mutations (fig 1, panels A and B). A C $\rightarrow \mathrm{T}$ transition in exon 5 at nt 434 changed a rather conserved threonine into isoleucine (T145I) (fig l, panel C). This base substitution changed a neutral amino acid into a hydrophobic amino acid at a putative casein II phosphorylation site. ${ }^{18}$ In addition, a $\mathrm{C} \rightarrow \mathrm{T}$ transition in exon 6 at nt 595 changed a highly conserved arginine into a tryptophan (R199W) (fig l, panel D). This base substitution transformed a basic amino acid residue with hydrophilic properties into a hydrophobic residue. Sequencing genomic DNA of the parents showed that the Rl99W mutation was inherited from the father and that the T145I mutation was inherited from the mother. The healthy brother carried the R199W mutation, but not the Tl45I mutation (not shown).
Sequencing genomic DNA from cultured amniocytes showed that the fetus was compound heterozygous for the T145I and the R199W mutations, a result which is consistent with the observation of a complex I deficiency in these cells (table 1).

The R199W mutation was absent from 100 chromosomes from healthy individuals from Réunion Island and from 100 control individuals from continental France. One healthy individual from Réunion Island but none from continental France was heterozygous for the T145I mutation. Noticeably, D-HPLC analysis did not reveal abnormal migration profiles in any of these individuals, suggesting that polymorphisms in this gene are rare. Both mutations were finally found to be absent from 58 patients with complex I deficiency, with no mutation in any of the mtDNA or nuclear genes (NDUFVI, NDUFV2, NDUFS1, NDUFS2, NDUFS4, NDUFS7, and NDUFS8) encoding complex I subunits.

\section{DISCUSSION}

In this report, we describe mutations of the NDUFS 3 gene in a case of late onset Leigh syndrome and complex I deficiency. The first evidence of encephalopathy with pyramidal and extrapyramidal symptoms was noted at nine years of age. Shortly after, MRI imaging detected focal, symmetrical, and necrotic lesions in the thalamus, brain stem, and white matter, suggestive of Leigh syndrome. Optic atrophy was noted as well. This was followed by progressive deterioration and death four years later.

The R199W mutation identified involved a conserved amino acid and was absent from healthy controls. On the other hand, the T145I mutation changed a neutral residue into a polar residue in a putative casein II phosphorylation site and was also absent from healthy individuals, except for one from Réunion Island who was heterozygous for this base change, with no other mutation. These amino acid changes therefore most probably represent disease causing mutations in the NDUFS3 protein.

Up to now, mutations in nuclear genes encoding complex I subunits (NDUFVl, NDUFS1, NDUFS4, NDUFS7, and NDUFS8) have been shown to cause neurological disease (Leigh or Leigh-like syndrome), ${ }^{5-11}{ }^{19}$ while heart involvement has been reported in patients harbouring mutations in two other nuclear genes encoding complex I subunits (NDUFS2 and NDUFV2). ${ }^{12}{ }^{13}$ To date, no simple explanation accounts for this clinical variability. The NDUFV1, NDUFV2, NDUFS1, NDUFS2, and NDUFS3 genes all encode subunits that are presumably involved in the catalysis of electron transfer from $\mathrm{NADH}$ to ubiquinone. The possibility that only part of these mutations results in superoxide overproduction has been proposed to explain specific cardiac involvement, as superoxide overproduction is known to readily trigger cardiomyocyte hypertrophy. ${ }^{20}$ On the other hand, differences in residual

Table 1 Polarographic and spectrophotometric assays of respiratory chain activity in patients and controls

\begin{tabular}{|c|c|c|c|c|c|c|c|c|}
\hline & \multirow{2}{*}{$\begin{array}{l}\text { Pyruvate (plus } \\
\text { malate) } \\
\text { oxidation }\end{array}$} & \multirow{2}{*}{$\begin{array}{l}\text { Succinate } \\
\text { oxidation }\end{array}$} & \multirow[t]{2}{*}{$\mathrm{Cl}$} & $\mathrm{Cll}+\mathrm{CIII}$ & CIII & CIV & \multirow{2}{*}{$\begin{array}{l}\text { Succinate/ } \\
\text { pyruvate } \\
\text { oxidation ratio }\end{array}$} & \multirow[b]{2}{*}{$\mathrm{CIV} / \mathrm{Cl}$ ratio } \\
\hline & & & & \multicolumn{3}{|c|}{ (nmol/min/mg protein) } & & \\
\hline \multicolumn{9}{|l|}{ Patient 1} \\
\hline $\begin{array}{l}\text { Skeletal muscle } \\
\text { mitochondria }\end{array}$ & $\begin{array}{l}20 \\
(94+48)\end{array}$ & ND & $\begin{array}{l}50 \\
(243+60)\end{array}$ & $\begin{array}{l}360 \\
(534+206)\end{array}$ & ND & $\begin{array}{l}2588 \\
(2582+686)\end{array}$ & ND & $\begin{array}{l}64.7 \\
(<18)\end{array}$ \\
\hline Cultured skin fibroblasts & $\begin{array}{l}2.7 \\
(3.3 \text { to } 6.8)\end{array}$ & $\begin{array}{l}7.8 \\
(6.5 \text { to } 14.3)\end{array}$ & $\begin{array}{l}16^{*} \\
(21 \text { to } 39)\end{array}$ & $\begin{array}{l}18 \\
(21 \text { to } 42)\end{array}$ & $\begin{array}{l}179^{*} \\
(126 \text { to } 211)\end{array}$ & $\begin{array}{l}344^{*} \\
(226 \text { to } 335)\end{array}$ & $\begin{array}{l}2.9 \\
(1.9 \pm 0.3)\end{array}$ & $\begin{array}{l}20.9^{*} \\
(9.6 \pm 1.4)\end{array}$ \\
\hline \multicolumn{9}{|l|}{ Patient 2 (fetus) } \\
\hline Cultured amniocytes & $\begin{array}{l}6.9 \\
(7.7 \text { to } 9.5)\end{array}$ & $\begin{array}{l}13.8 \\
(8.8 \text { to } 13.6)\end{array}$ & - & - & $\begin{array}{l}67 \\
(60 \text { to } 95)\end{array}$ & $\begin{array}{l}96 \\
\text { (68 to } 97)\end{array}$ & $\begin{array}{l}2.0 \\
(1.3 \pm 0.2)\end{array}$ & - \\
\hline
\end{tabular}

Bold letters denote abnormal values. Determinations were done in three different investigation centres using their own reference values, as indicated in the brackets. However, all investigations resulted in a similar conclusion, that there was complex I deficiency causing decreased pyruvate plus malate oxidation. *Values obtained after treatment of cultured skin fibroblasts with digitonin and Percoll, as recently described. ${ }^{15}$ 


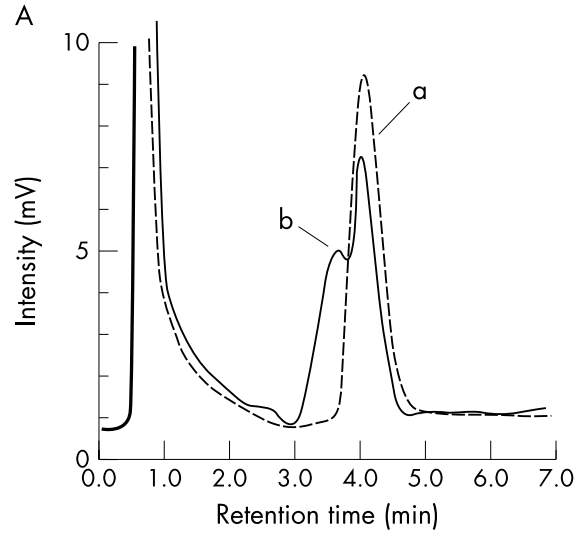

C
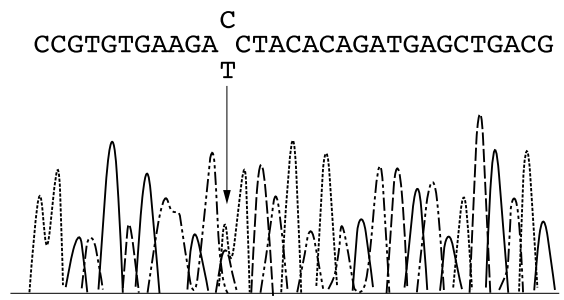

$E$

H sapiens

$B$ taurus

N crassa

Y lipotityca

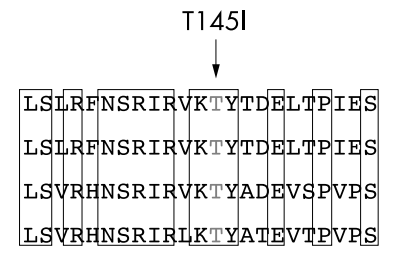

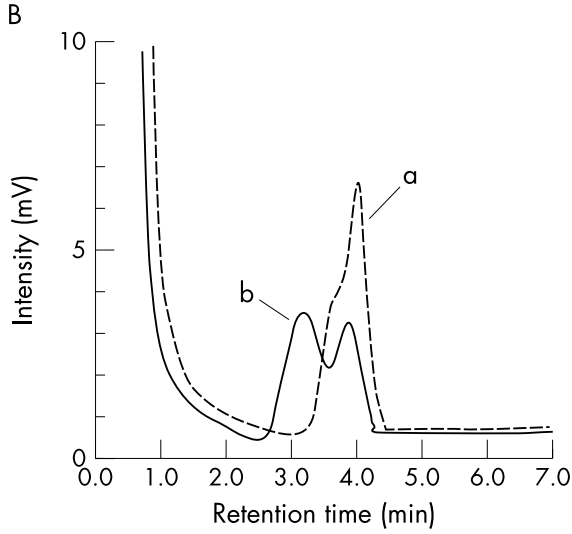

D

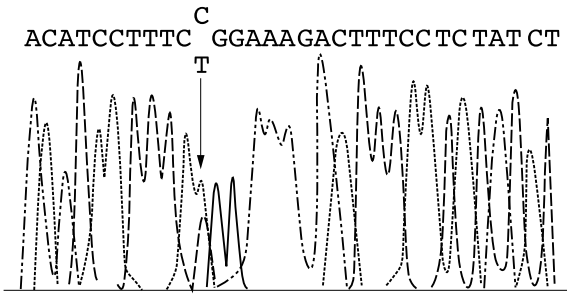

$\mathrm{F}$

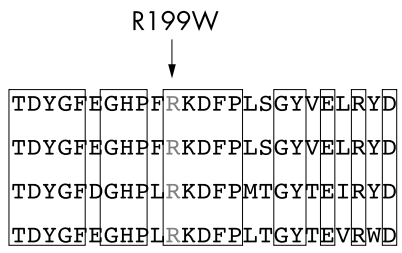

Figure 1 Molecular analysis of the NDUFS3 gene in patient 1 and control fibroblasts. (A) D-HPLC pattern of NDUFS3 fragment 1 of control fibroblasts (a) and patient fibroblasts (b). (B) D-HPLC pattern of NDUFS3 fragment 2 of control fibroblasts (a) and patient fibroblasts (b). (C, D) Sequence analysis done on fibroblast cDNA from patient 1. (E, F) Sequence alignment of the NDUFS3 proteins from various species. Boxes indicate conserved amino acids. Arrows show the mutated amino acids T145I in fragment 1 (E) and R199W in fragment 2 (F).

complex I activity compromising cell specific functions should be also considered.

With this mutation report in the NDUFS3 gene, disease causing mutations have now been described in all the 14 genes (seven mitochondrial and seven nuclear) encoding the core subunits of complex I and considered essential for catalysing electron transfer from NADH to ubiquinone, and for the generation of the proton motive force. These genes are the most conserved across species, from mammals to bacteria, and the encoded proteins contain all the known redox centres of the enzyme, as well as substrate binding sites. These 14 subunits have been defined as the "minimal enzyme," while other subunits are often referred to as "supernumerary.", 21 Among the "supernumerary" subunits, only the NDUFS4 gene has been found mutated in humans. The NDUFS4 subunit is involved in the regulation of complex I activity, with phosphorylation at a cAMP dependent protein kinase consensus site that was found to stimulate complex I activity. The function of the remaining 28 "supernumerary" subunits is unknown so far. These latter subunits may play various different roles, including protection of the complex against oxidative injury, regulation of activity, and assembly or stabilisation of the complex, but alternative functions remain conceivable.

\section{ACKNOWLEDGEMENTS}

We thank the Association Française contre les Myopathies (AFM) and Association contre les Maladies Mitochondriales (AMMI) for constant support, and acknowledge the financial support of the European Commission (QLG1-CT-2001-00966).

\section{Authors' affiliations}

P Bénit, I Giurgea, D Chretien, S Lebon, A Munnich, A Rötig, P Rustin, Unité de Recherche sur les Handicaps Génétiques de l'Enfant (INSERM U393) and Département de Génétique, Hôpital Necker-Enfants Malades, Paris Cedex 15, France

A Slama, Laboratoire de Biochimie 1, AP-HP Hôpital de Bicêtre, Le Kremlin Bicêtre Cedex, France

F Cartault, Centre Hospitalier Départemental Félix Guyon, Service Génétique Bellepierre, Saint-Denis Cedex, La Réunion, France C Marsac, CERTO Faculté Necker-Enfants Malades, Paris Cedex 15

Correspondence to: Dr Pierre Rustin, INSERM U393, Hôpital NeckerEnfants Malades, 149 rue de Sèvres, 75015 Paris, France; rustin @ necker.fr

Received 9 September 2003

Accepted 15 October 2003

\section{REFERENCES}

1 Fearnley IM, Walker JE. Conservation of sequences of subunits of mitochondrial complex I and their relationships with other proteins. Biochim Biophys Acta 1992:1140:105-34.

2 Galante YM, Hatefi Y. Purification and molecular and enzymic properties of mitochondrial NADH dehydrogenase. J Biol Chem 1979;255:5530-7.

3 Hirst J, Carroll J, Fearnley IM, Shannon RJ, Walker JE. The nuclear encoded subunits of complex I from bovine heart mitochondria. Biochim Biophys Acta 2003; 1604:135-50. 
4 DiMauro $S$ Schon EA. Mitochondrial DNA mutations in human disease. Am J Med Genet 2001;106:18-26.

5 Loeffen J, Smeitink J, Triepels R, Smeets R, Schuelke M, Sengers R, Triibels F, Hamel B, Mullaart R, van den Heuvel L. The first nuclear-encoded complex I mutation in a patient with Leigh syndrome. Am J Hum Genet 1998;63:1598-608

6 van den Heuvel L, Ruitenbeek W, Smeets R, Gelman-Kohan Z, Elpeleg O, Loeffen J, Trijbels F, Mariman E, de Bruiin D, Smeitink J. Demonstration of a new pathogenic mutation in human complex I deficiency: a 5-bp duplication in the nuclear gene encoding the 18-kD (AQDQ) subunit. Am J Hum Genet 1998;62:262-8.

7 Budde SM, van den Heuvel LP, Janssen AJ, Smeets RJ, Buskens CA, DeMeirleir L, Van Coster R, Baethmann M, Voit T, Triibels JM, Smeitink JA. Combined enzymatic complex I and III deficiency associated with mutations in the nuclear encoded NDUFS4 gene. Biochem Biophys Res Commun 2000;275:63-8.

8 Petruzzella V, Vergari R, Puzziferri I, Boffoli D, Lamantea E, Zeviani M, Papa S. A nonsense mutation in the NDUFS4 gene encoding the $18 \mathrm{kDa}$ (AQDQ) subunit of complex I abolishes assembly and activity of the complex in a patient with Leigh-like syndrome. Hum Mol Genet 2001 ; 10:529-35.

9 Triepels RH, van den Heuvel LP, Loeffen JL, Buskens CA, Smeets RJ, Rubio Gozalbo ME, Budde SM, Mariman EC, Wijburg FA, Barth PG, Triibels JM, Smeitink JA. Leigh syndrome associated with a mutation in the NDUFS7 (PSST) nuclear encoded subunit of complex I. Ann Neurol 1999:45:787-90.

10 Schuelke M, Smeitink J, Mariman E, Loeffen J, Plecko B, Trijbels F, StocklerIpsiroglu S, van den Heuvel L. Mutant NDUFV1 subunit of mitochondrial complex I causes leukodystrophy and myoclonic epilepsy. Nat Genet 1999:21:260-1.

11 Benit P, Chretien D, Kadhom N, de Lonlay-Debeney P, Cormier-Daire V, Cabral A, Peudenier S, Rustin P, Munnich A, Rotig A. Large-scale deletion and point mutations of the nuclear NDUFV1 and NDUFS1 genes in mitochondrial complex I deficiency. Am J Hum Genet $2001 ; 68: 1344-52$.

12 Loeffen J, Elpeleg O, Smeitink J, Smeets R, Stockler-lpsiroglu S, Mandel H, Sengers R, Trijbels F, van den Heuvel L. Mutations in the complex I NDUFS2 gene of patients with cardiomyopathy and encephalomyopathy. Ann Neurol 2001;49:195-201.
13 Benit P, Beugnot R, Chretien D, Giurgea I, De Lonlay-Debeney P, Issartel JP, Corral-Debrinski M, Kerscher S, Rustin P, Rotig A, Munnich A. Mutant NDUFV2 subunit of mitochondrial complex I causes early onset hypertrophic cardiomyopathy and encephalopathy. Hum Mutat 2003;21:582-6.

14 Rustin P, Chretien D, Bourgeron T, Gerard B, Rotig A, Saudubray JM Munnich A. Biochemical and molecular investigations in respiratory chain deficiencies. Clin Chim Acta 1994;228:35-51.

15 Chretien D, Benit P, Chol M, Lebon S, Rotig A, Munnich A, Rustin P. Assay of mitochondrial respiratory chain complex I in human lymphocytes and cultured skin fibroblasts. Biochem Biophys Res Commun 2003;301:222-4.

16 Chretien D, Gallego J, Barrientos A, Casademont J, Cardellach F, Munnich A Rotig A, Rustin P. Biochemical parameters for the diagnosis of mitochondrial respiratory chain deficiency in humans, and their lack of age-related changes. Biochem J 1998;329:249-54.

17 Geromel V, Parfait B, von Kleist-Retzow JC, Chretien D, Munnich A, Rotig A, Rustin $P$. The consequences of a mild respiratory chain deficiency on substrate competitive oxidation in human mitochondria. Biochem Biophys Res Commun 1997;236:643-6.

18 Loeffen J, Van den Heuvel L, Smeets R, Triepels R, Sengers R, Triibels F, Smeitink J. cDNA Sequence and chromosomal localisation of the remaining three human nuclear encoded iron sulphur protein (IP) subunits of complex I: The human IP fraction is completed. Biochem Biophys Res Commun 1988;247:751-8.

19 Benit P, Steffann J, Lebon S, Chretien D, Kadhom N, de Lonlay P, Goldenberg A, Dumez Y, Dommergues M, Rustin P, Munnich A, Rotig A. Genotyping microsatellite DNA markers at putative disease loci in inbred/ multiplex families with respiratory chain complex I deficiency allows rapid identification of a novel nonsense mutation (IVS 1 nt -1) in the NDUFS4 gene in Leigh syndrome. Hum Genet 2003;1 12:563-6.

20 Siwik DA, Tzortzis JD, Pimental DR, Chang DL, Pagano PJ, Singh K, Sawver DB, Colucci WS. Inhibition of copper-zinc superoxide dismutase induces cell growth, hypertrophic phenotype, and apoptosis in neonatal rat cardiac myocytes in vitro. Circ Res 1999:85:147-53.

21 Kerscher S, Kashani-Poor N, Zwicker K, Zickermann V, Brandt U. Exploring the catalytic core of complex I by Yarrowia lipolytica yeast genetics. J Bioenerg Biomembr 2001;33:187-96.

\section{$\mathrm{ECHO}$}

\section{Growing up abolishes a genetic protection against asthma}

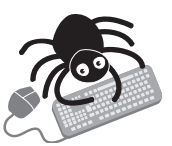

Please visit the Journal of Medical Genetics website [www. jmedgenet. com] for a link to the full text of this article.
$\mathrm{R}$ esearchers have discovered that the CCR5 432 mutation loses its protective effect against asthma as children mature. This may explain conflicting results and means that future association and linkage studies must take account of age as a confounder. The researchers went back to a population of schoolchildren aged 8-12 years they studied in 1989 and followed up all those available 10 years later -627 of the original 3406 sampleto determine whether as adults their asthma, wheezing, and atopy status had changed according to their mutation status.

Carrying the deletion significantly reduced the risk of having current asthma in childhood (odds ratio (OR) 0.31 (95\% confidence interval 0.14 to 0.72 )) but not in adulthood (OR 0.88 (95\% CI 0.52 to 1.48$)$ ), according to logistic regression corrected for atopy (in 1989) and sex. CCR5 432 was not associated with current atopy in either study. Wheezing in childhood had the lowest frequency of heterozygous or homozygous carriers whereas wheezing developing in adults or persisting from childhood had a much higher frequency compared with controls without asthma. Overall carrier frequency for CCR5 432 was $19 \%$, and the population was in Hardy-Weinberg equilibrium. Mean age was 20 (range 18-22) years, and the two samples were reasonably similar.

The researchers had shown that children aged 5-15 years with CCR5432 mutation were protected from asthma. Contradictory findings from other studies led them to test whether protection might be age dependent. The deletion stops expression of a chemokine receptor on the surface of $\mathrm{T}$ helper 1 cells.

A Thorax 2003;58:222-226. 